\title{
Bovine papillomavirus type 2 detection in the urinary bladder of cattle with chronic enzootic haematuria
}

\author{
Sheila R Wosiacki, Marlise P Claus, Alice F Alfieri, Amauri A Alfieri ${ }^{+}$ \\ Laboratório de Virologia Animal, Departamento de Medicina Veterinária Preventiva, Universidade Estadual de Londrina, \\ 86051-990 Londrina, PR, Brasil
}

\begin{abstract}
The bovine papillomavirus type $2(B P V-2)$ involvement in the aetiology of chronic enzootic haematuria associated to bracken fern ingestion has been suggested for a long time. However, a few reports have shown the presence of the BPV-2 in urinary bladder tumors of cattle. The aim of this study was to investigate the presence of the BPV-2 infection in the urinary bladder of cattle with chronic enzootic haematuria in Brazilian cattle herds. Sixty-two urinary bladders were collected from adult cattle in beef herds from the north region of the state of Paraná, Brazil. According to clinical and pathological finds the specimens were distributed in three groups: the group A was constituted by 22 urinary bladders with macroscopic lesions collected at necropsy of cattle with clinical signs of chronic enzootic haematuria; the group B by 30 urinary bladders with macroscopic lesions collected in a slaughterhouse of cows coming from bracken fern-endemic geographical region; and the group C (control) by 10 urinary bladders without macroscopic lesions collected from asymptomatic cattle in a bracken fern-free geographical region. By a semi-nested polymerase chain reaction (PCR) assay, with an internal control, a fragment of the BPV-2 $L 1$ gene with 386 bp length was amplified in $36(58 \%)$ urinary bladder. The rate of $B P V-2$ positive urinary bladders was $50 \%$ (11/22) for group $A, 80 \%$ (24/30) for group $B$, and 10\% (1/10) for group $C$ (control). The rate of the positive results found in groups $A$ and $B$ that included urinary bladder samples with macroscopic lesions was $67 \%$ $(35 / 52)$ and the detection of the BPV-2 in both groups was significantly higher $(P<0.05)$ than in the control group. RFLP with Rsa I and Hae III enzymes evaluated the specificity of the BPV-2 amplicons. The PCR internal control that amplified a $626 \mathrm{bp}$ fragment of the ND5 gene of the bovine mitochondrial genome was amplified in all analyzed samples and excluded false-negatives or invalid results in the semi-nested PCR. These results suggest the BPV-2 involvement in the chronic enzootic haematuria aetiology and open the perspective of the development of new strategies for the control of this disease that is the major cause of economical losses in beef herds from many Brazilian geographical regions.
\end{abstract}

Key words: cattle-viruses - urinary bladder - chronic enzootic haematuria - bovine papillomavirus type 2 semi-nested-polymerase chain reaction

The chronic enzootic haematuria causes high economical losses in cattle herds around the world. The disease is clinically characterized by intermittent haematuria caused by malignant lesions in the urinary bladder, followed by anemia, progressive emaciation, and death (Hopkins 1986).

The bovine papillomavirus type 2 (BPV-2) infection and the chronic intoxication by bracken fern (Pteridium aquilinum sub. caudatum var. arachnoideum) ingestion were associated with urinary bladder lesions and the clinical signs of chronic enzootic haematuria in adult cattle. Evidences indicate that the malignant progression of urinary bladder lesions is dependent on an inter-relationship between the BPV-2 infection and carcinogenic, mutagenic, and immunosuppressive compounds of the bracken fern (Reddy \& Fialkow 1983, Campo 1995, 1997). However, few studies were accomplished on the aetiological aspects of chronic enzootic haematuria, and the

\footnotetext{
${ }^{+}$Corresponding author and research fellowship: CNPq, Capes, Fundação Araucária.E-mail: alfieri@uel.br

Received 7 March 2006

Accepted 7 June 2006
}

aetiology and pathogeny of this disease are not yet completely known.

The BPV-2 is a small oncogenic DNA virus member of the genus Deltapapillomavirus in the Papillomaviridae family (Fauquet et al. 2004). It is a fibropapillomavirus that can cause common skin papillomas, fibropapillomas in the alimentary tract and in the urinary bladder of cattle (Campo 1997). The diagnosis of the BPV-2 infection has been made through the identification of the viral DNA in tissue fragments using techniques such as the Southern blot and the polymerase chain reaction (PCR) (Campo et al. 1992, Bloch et al. 1997, Borzacchiello et al. 2003, Wosiacki et al. 2005).

Due to the importance of chronic enzootic haematuria in cattle herds, mainly in beef cows, from different regions around the world studies to contribute with the definition of the urinary bladder neoplastic lesions aetiology are necessary. This study was carried out with the objective to detect BPV-2 in urinary bladder of cattle with macroscopic lesions of chronic enzootic haematuria collected in necropsies and in slaughterhouses from bracken fernendemic geographical region.

\section{MATERIALS AND METHODS}

Positive control - As BPV-2 positive control a skin papilloma sample from the cervico-dorsal area of a seven- 
month-old calf was used. The macroscopic aspects and the histopathological findings were similar to the skin fibropapillomas caused by the BPV-2. The BPV-2 L1 gene was identified in this skin papilloma sample by a seminested PCR (SN-PCR) assay, and characterized by using of restriction fragment length polymorphism (RFLP) and sequence analysis (Wosiacki et al. 2005).

Specimens collection - Sixty-two urinary bladders were collected from adult cows in beef cattle herds from the north region of the state of Paraná, Brazil. According to clinical and pathological finds the specimens were distributed in three groups: (i) the group A containing 22 urinary bladders with macroscopic hyperplasic and hemorrhagic lesions collected at necropsy of cows with clinical signs of chronic enzootic haematuria; (ii) the group B consisted of 30 urinary bladders with macroscopic lesions collected in slaughterhouses of cows coming from bracken fern-endemic geographical region; (iii) the group $\mathrm{C}$ (control) was constituted of 10 urinary bladders without macroscopic lesions collected in a slaughterhouse from asymptomatic cattle in a bracken fern-free geographical region.

$B P V-2$ detection - Fragments of urinary bladder samples were triturated in phosphate-buffered saline (PBS, $\mathrm{pH} 7.2)$ and the suspensions $(10-20 \% \mathrm{w} / \mathrm{v})$ were centrifuged for $15 \mathrm{~min}$ at $1500 \mathrm{~g}$ at $4^{\circ} \mathrm{C}$. Aliquots of $250 \mu \mathrm{l}$ of the supernatant were treated with lysis buffer (10 mM Tris; 1 mM EDTA; 0.5\% Nonidet P40; 1\% SDS; and $0.001 \mathrm{mg}$ proteinase $\mathrm{K}$ ). After homogenization, the samples were incubated at $56^{\circ} \mathrm{C}$ for $30 \mathrm{~min}$. For DNA extraction a combination of phenol/chloroform/isoamyl alcohol and silica/ guanidine isothiocyanate methods was performed according to Alfieri et al. (2004). First, the samples were treated with an equal volume of phenol/chloroform/isoamyl alcohol (25:24:1), homogenized, and heated at $56^{\circ} \mathrm{C}$ for $15 \mathrm{~min}$ (Sambrook \& Russell 2001). Next, the samples were centrifuged at $10,000 \mathrm{~g}$ for $10 \mathrm{~min}$ and the aqueous phase processed in silica/guanidine isothiocyanate (Boom et al. 1990). The DNA was eluted in $125 \mu$ l of ultrapure (Milli$\mathrm{Q}^{\circledR}$ ) sterile water and stored at $-20^{\circ} \mathrm{C}$ until use. Aliquots of ultrapure sterile water were included as negative controls in all the DNA extraction procedures.

The BPV-2 L1 gene detection was carried out by a SNPCR performed according to Wosiacki et al. (2005). In the first round (PCR), the BPVP1 (5-TGTTCC CAAAGT GTC TG-3, nt. 5771-5787) and BPVP2 (5-CAT TTT GAG GTA GTC TGG-3, nt. 6299-6282) primers were used to amplify a fragment of $529 \mathrm{bp}$. In the second round (SN-PCR) the BPVP1 primer and the BPVP3 (5-ATT CTAAAG GAG GAC ACG-3, nt. 6156-6139) primer amplify a 386 bp size fragment. In the first round all the reactions were carried out with internal control primers BOV1 (5-ATA CGC CTT CAT TAC CAG-3, nt. 12.231-12.248), and BOV 2 (5-TTG AAT GGA GTA GTG CTG-3, nt. 12.856-12.839) that amplified a $626 \mathrm{bp}$ fragment of the ND5 gene of the bovine mitochondrial genome that was used in a multiplex reaction.

In the PCR assay $2.5 \mu \mathrm{l}$ of extracted DNA, $0.4 \mathrm{pmol}$ of each BPVP1, BPVP2, BOV1, and BOV2 primers, $1 \times$ PCR buffer (20 mM Tris-HCl pH 8.4 and $50 \mathrm{mM} \mathrm{KCl}), 2.5 \mathrm{mM}$ $\mathrm{MgCl}_{2}, 300 \mu \mathrm{M}$ each dNTP (Invitrogen ${ }^{\mathrm{TM}}$ Life Technologies, US), 1.25 units of Platinun Taq DNA Polymerase $\left(\right.$ Invitrogen ${ }^{\mathrm{TM}}$ ) and ultrapure sterile water to a final volume of $25 \mu \mathrm{l}$ were used. The amplification was performed in a thermocycler (PTC 200 - MJ Research Co. Water Town, MA, US) and consisted of the following time and temperature conditions: one step of $2 \mathrm{~min} / 94^{\circ} \mathrm{C}$ followed by 40 cycles at $1 \mathrm{~min} / 94^{\circ} \mathrm{C}, 1 \mathrm{~min} / 55^{\circ} \mathrm{C}$ and $1 \mathrm{~min} / 72^{\circ} \mathrm{C}$. For the SN-PCR $1 \mu 1$ of PCR product, 0.4 pmol of BPVP1 and BPVP3 primers, $1 \times \mathrm{PCR}$ buffer, $2 \mathrm{mM} \mathrm{MgCl}, 100 \mu \mathrm{M}$ each dNTP, 0.75 units of Platinum Taq DNA Polymerase, and ultrapure sterile water to a final volume of $25 \mu 1$ were used. The conditions of amplification consisted in one step of 2 $\min / 94^{\circ} \mathrm{C}$ followed by 30 cycles at $30 \mathrm{~s} / 94^{\circ} \mathrm{C}, 30 \mathrm{~s} / 55^{\circ} \mathrm{C}$, and $1 \mathrm{~min} / 72^{\circ} \mathrm{C}$.

The RFLP was assessed by the analysis of the BPV-2 SN-PCR amplicons with the Rsa I and Hae III enzymes (Invitrogen ${ }^{\mathrm{TM}}$ ). The digestion was made during $1 \mathrm{~h}$ at $37^{\circ} \mathrm{C}$ according to manufacturer's instructions.

Amplicons of SN-PCR and RFLP were analyzed by electrophoresis in a 2.5\% agarose gel in TBE buffer $\mathrm{pH} 8.4$ ( $89 \mathrm{mM}$ Tris; $89 \mathrm{mM}$ boric acid; $2 \mathrm{mM}$ EDTA) stained with $0.5 \mu \mathrm{g} / \mathrm{ml}$ ethydium bromide and visualized under UV light.

Statistical analysis - The association between the BPV2 detection in urinary bladder samples and the three groups included in this study was analyzed by the Chi-Square $\left(\chi^{2}\right)$ or the Fisher exact test. The statistical analysis was done using the software EpiInfo 3.3.2 significance level of $5 \%$.

\section{RESULTS}

A 386 bp specific amplicon of the BPV-2 L1 gene was detected in 58\% (36/62) (IC 95\% $=44.84-77.48)$ of the urinary bladder samples (Fig. 1). The Table shows the distribution of SN-PCR positive results by group (A, B, and C) of cattle included in this study. The rate of BPV-2 positive urinary bladder with macroscopic lesions $(n=52$, groups $A$ and B) was $67 \%$. In the control group $C$ in which only urinary bladder samples without macroscopic lesions were included, the rate of BPV-2 positive samples was $10 \%$. The association of BPV-2 diagnosis in urinary bladders and macroscopic lesions was significant $(P=0.0003)$.

The specificity of the L1 gene amplicons was confirmed by RFLP. As in silico analysis the amplicon of 386 bp yielded fragments of 85 and 301 bp length with Rsa I, and of 147 and $239 \mathrm{bp}$ with Hae III enzymes (Fig. 2).

A $626 \mathrm{bp}$ fragment of internal control was amplified in the first amplification round in all clinical samples included in this study.

\section{DISCUSSION}

The involvement of papillomaviruses in the aetiology of chronic enzootic haematuria associated to bracken fern ingestion has been suggested for a long time (Jarrett et al. 1978, Pachauri et al. 1981, Moura et al. 1988). However, the difficulty of the BPV diagnosis by conventional virological methods, such as virus isolation in cell culture, stimulated the development and assessment of molecular diagnostic techniques and some reports have shown the involvement of the BPV-2 in the aetiology of urinary bladder neoplastic lesions in cattle (Campo et al. 1992, Stocco dos Santos et al. 1998, Borzacchiello et al. 2003, Wosiacki et al. 2005). 


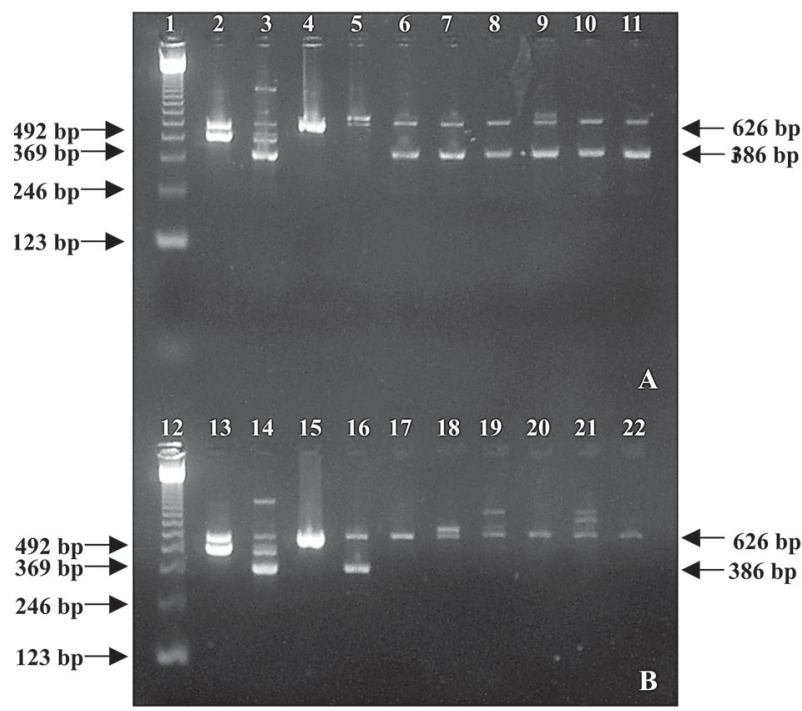

Fig. 1: bovine papillomavirus type 2 detection by a semi-nestedpolymerase chain reaction (PCR) assay, with a internal control (626 bp), in urinary bladder samples from cattle with and without chronic enzootic haematuria. A: urinary bladder samples from animals with clinical signs of enzootic haematuria. Lanes - 1: $123 \mathrm{bp}$ ladder (Invitrogen ${ }^{\mathrm{TM}}$ Life Technology, US); 2 and 3: skin papilloma (positive control), PCR (lane 2) and SN-PCR (lane 3); 4: PCR of urinary bladder sample; 5 to 11: SN-PCR of urinary bladder samples (386 bp); B: urinary bladder samples from asymptomatic cattle. Lanes - 12: 123 bp ladder; 13 and 14: skin papilloma (positive control), PCR (lane 13) and SN-PCR (lane 14); 15: PCR of urinary bladder sample; 16 to 22 : SN-PCR of urinary bladder samples.

In this study we used a SN-PCR assay to assess the presence of the BPV-2 in the urinary bladder samples with hyperplasic and hemorrhagic macroscopic lesions collected from adult cattle in geographical regions where the chronic enzootic haematuria is endemic in cattle herds. All these samples were obtained from cows raised in highly infested pastures with bracken fern and in a geographical region where the chronic enzootic haematuria clinical disease is frequent and represent the major cause of mortality, mainly in cows from beef herds.

Campo et al. (1992) detected the BPV-2 DNA by a Southern blot assay in $46 \%$ ( 7 of 15 ) of the natural tumors cases and in $69 \%$ (9 of 13) of the experimentally induced lesions in immunosuppressed animals, suggesting a close

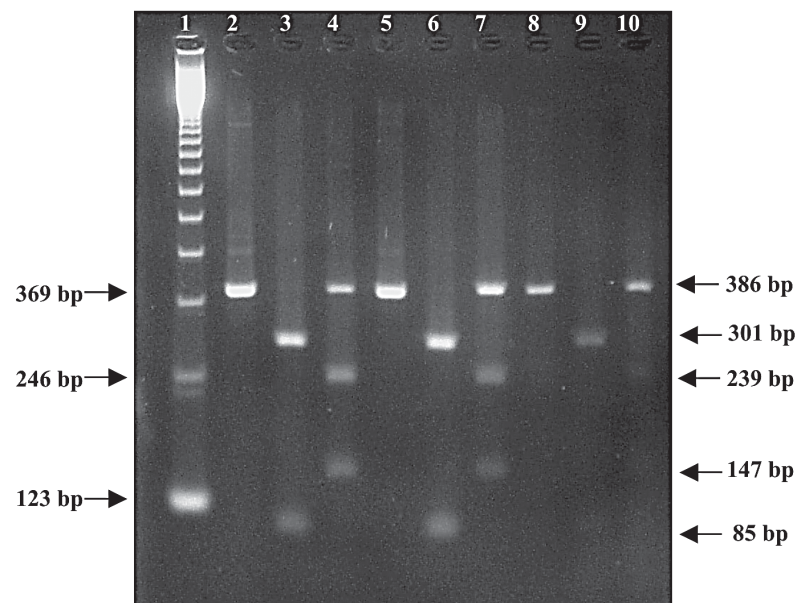

Fig. 2: restriction fragment length polymorphism (RFLP) of bovine papillomavirus type $2 \mathrm{~L} 1$ gene amplicons. Lanes - 1: $123 \mathrm{bp}$ ladder (Invitrogen ${ }^{\mathrm{TM}}$ Life Technology, US); 2 to 4: skin papilloma (positive control), BPV-2 amplicon (lane 2), RFLP with Rsa I (lane 3) and Hae III (lane 4) enzymes; 5 to 7: urinary bladder sample from a cow with chronic enzootic haematuria, BPV-2 amplicon (lane 5), RFLP with Rsa I (lane 6) and Hae III (lane 7) enzymes; 8 to 10: urinary bladder sample from asymptomatic cattle, BPV-2 amplicon (lane 8), RFLP with Rsa I (lane 9) and Hae III (lane 10) enzymes.

association between BPV-2 and bovine bladder tumor. Twenty percent of positive samples were found in the control group, suggesting the viral persistence that can be activated when the animal is exposed to the bracken co-carcinogens and immunosuppressants compounds.

In Italy, Borzacchiello et al. (2003) detected the BPV-2 by a PCR assay in 76.7\% (46/60) and 50\% (17/34) of cattle urinary bladder samples with and without neoplastic lesions, respectively. Their control group consisted of urinary bladder samples without macroscopic lesions. However, these samples were obtained in the same endemic geographical area as the urinary bladders with macroscopic lesions, which explain the high rate of positive samples in the control group

The detection rate of papillomaviruses DNA in urinary bladder samples with lesions varies substantially in different studies. The major problem may be discrepancies in the number of samples assessed, in the diagnostic techniques, and in the interpretation of the result. How-

TABLE

Bovine papillomavirus type 2 detection by semi-nested-polymerase chain reaction in urinary bladder samples associated with macroscopic lesions and clinical signs of the chronic enzootic haematuria

\begin{tabular}{llccccc}
\hline & & Macroscopic & \multicolumn{2}{c}{ Bracken } & \multicolumn{2}{c}{ Semi-nested PCR (\%) } \\
Groups & Clinical sign & lesions ${ }^{a}$ & fern ${ }^{b}$ & Positive & Negative & Total \\
\hline A & Chronic enzootichaematuria & + & + & $11(50)$ & $11(50)$ & 22 \\
B & Not assess & + & + & $24(80)$ & $6(20)$ & 30 \\
C & Asymptomatic & - & - & $1(10)$ & $9(90)$ & 10 \\
\hline Total & & & & $36(58)$ & $26(42)$ & 62 \\
\hline
\end{tabular}

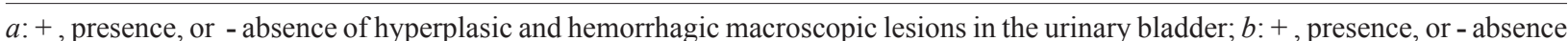
of bracken fern in the pastures; $\mathrm{A} \times \mathrm{B} \times \mathrm{C}: \chi^{2}=16 ; P=0.0003 ; \mathrm{A} \times \mathrm{B}$ : Chi-Square Yates corrected $\chi^{2}=3.92 ; P=0.0477 ; \mathrm{A} \times \mathrm{C}:$ Fisher exact $P=0.0496 ; \mathrm{B} \times \mathrm{C}$ : Fisher exact $P=0.0001$ 
ever, in this study SN-PCR false-negatives results were not generated by nucleic acid extraction failure, variable (low or high) amounts of DNA or by the presence of inhibitors of the PCR reaction. The internal control of the PCR reaction was amplified in all the urinary bladder samples.

The papillomaviruses DNA persists in tumor cells in episomal and/or integrative forms (Klimov et al. 2002). Although viral DNA remains exclusively episomal in benign papillomas, integration of a partially deleted viral genome is present in most human cervical cancers. Integration of human papillomavirus (HPV) DNA into the host genome occurs early in cancer development and is probably an important event in malignant transformation of cervical cancer (Cullen et al. 1991, Yoshinouchi et al. 1999, Lukaszuk et al. 2003). For BPV-2, no studies of the phenomenon of viral integration in samples of urinary bladder tumors were found. However the genetic analyses of BPV-2 and BPV-1 have demonstrated the highest homology and similarity of these viruses. Genetic studies have mapped the BPV-1 and three independent transforming proteins were found and encoded as E5, E6, and E7 genes. The E5 gene is the major transforming gene of BPV-1. This gene is highly conserved among the group of papillomaviruses and can affect the activity and metabolism of growth factor receptors (Campo 2002).

Studies in animal model have clearly demonstrated the contribution of host genetics, chemical carcinogens, and immunosuppression to the conversion of papillomaviruses induced benign lesions into malignant tumors. Most of the papillomaviruses basic knowledge is resulting from the BPV study. In some geographical regions around the world the chronic enzootic haematuria is a major cause of death in adult cattle, and no treatment is known for this disease at the moment. However, few epidemiological researches about this disease have been accomplished.

The evidence of this study contributed with the demonstration of the viral aetiology in chronic enzootic haematuria of cattle herds in north region of the state of Paraná, Brazil. The studies for the definition of viral aetiology of chronic enzootic haematuria can contribute for proposals of vaccine development for the BPV-2 infection control in herds from endemic regions and also to reduce the severity of chronic enzootic haematuria clinical signs in cattle around the world.

\section{REFERENCES}

Alfieri AF, Alfieri AA, Barreiros MAB, Leite JPG, Richtzenhain LJ 2004. G and P genotypes of group A rotavirus strains circulating in calves in Brazil, 1996-1998. Vet Microbiol 99: 167-173.

Bloch N, Sutton RH, Breen M, Spradbrow PB 1997. Identification of papillomavirus in scrapings from bovine warts by use of the polymerase chain reaction. Vet Res Comm 21: 63-68.

Boom R, Sol CJA, Salimans MMM, Jansen CL, Wertheim-Van Dillen PME, Noordaa J van der 1990. Rapid and simple method for purification of nucleic acids. J Clin Microbiol 28: 495-503.

Borzacchiello G, Iovane G, Marcante ML, Poggiali F, Roperto F, Roperto S, Venuti A 2003. Presence of bovine papillomavirus type 2 DNA and expression of the viral onco- protein E5 in naturally occurring urinary bladder tumours in cows. J Gen Virol 84: 2921-2926.

Campo MS 1995. Infection by bovine papillomavirus and prospects for vaccination. Trends Microbiol 3: 92-97.

Campo MS 1997. Review bovine papillomavirus and cancer. Vet J 154: 175-188.

Campo MS 2002. Animal models of papillomavirus pathogenesis. Virus Res 89: 249-261.

Campo MS, Jarrett WFH, Barron R, O'Neil BW, Smith KT 1992. Association of bovine papillomavirus type 2 and bracken fern with bladder cancer in cattle. Cancer Res 52: 6898-6904.

Cullen AP, Reid R, Campion M, Lörincz AT 1991. Analysis of the physical state of different human papillomavirus DNAs in intraepithelial and invasive cervical neoplasm. $J$ Virol 65: 606-612.

Fauquet CM, Mayo MA, Maniloff J, Desselberger U, Ball LA 2004. Virus Taxonomy, Academic Press, San Diego, 1162 $\mathrm{pp}$.

Hopkins NCG 1986. Aetiology of enzootic haematuria. Vet Rec 118: 715-717.

Jarrett WF, McNeil PE, Grimshaw WT, Selman IE, McIntyre WI 1978. High incidence area of cattle cancer with a possible interaction between an environmental carcinogen and a papilloma virus. Nature 20: 215-217.

Klimov E, Vinokourova S, Moisjak E, Rakhmanaliev E, Kobseva V, Laimins L, Kisseljov F, Sulimova G 2002. Human papilloma viruses and cervical tumours: mapping of integration sites and analysis of adjacent cellular sequences. BMC Cancer 2: 24.

Lukaszuk K, Liss J, Wozniak I, Emerich J, Wójcikowski C 2003. Human papillomavirus Type 16 status in cervical carcinoma cell DNA assayed by multiplex PCR. J Clin Microbiol 41: 608-612.

Moura JW, Stocco dos Santos RC, Dagli ML, D'Angelino JL, Birgel EH, Beçak W 1988. Chromosome aberrations in cattle raised on bracken fern pasture. Experientia 15: 785788.

Pachauri SP, Sharma UK, Joshi HC, 1981. Note on pathological studies on the urinary bladder tumours of cattle with chronic haematuria. Indian J Anim Sci 51: 898-900.

Reddy AL, Fialkow PJ 1983 Papillomas induced by initiationpromotion differ from those induced by carcinogen alone. Nature 13: 69-71.

Sambrook J, Russell DW, 2001. Molecular Cloning: A Laboratory Manual, Cold Spring Harbor Laboratory, New York, $999 \mathrm{pp}$.

Stocco dos Santos RCS, Lindsey CJ, Ferraz OP, Pinto JR, Mirandola RS, Benesi FJ, Birgel EH, Pereira CAB, Beçak W 1998. Bovine papillomavirus transmission and chromosomal aberrations: on experimental model. J Gen Virol 79: 2127-2135.

Wosiacki SR, Barreiros MAB, Alfieri AF, Alfieri AA 2005. Seminested-PCR for detection and typing of bovine papillomavirus type 2 in urinary bladder and whole blood from cattle with enzootic haematuria. J Virol Meth 126: 215-219.

Yoshinouchi M, Hongo A, Nakamura K, Kodama J, Itoh S, Sakai H, Kudo T 1999. Analysis by multiplex PCR of the physical status of human papillomavirus type 16 DNA in cervical cancers. J Clin Microbiol 37: 3514-3517. 